\title{
The Place of the Family House in Contemporary Oyo Town, Nigeria
}

\author{
Adesoji David JIBOYE(Corresponding author) \& Lee OGUNSHAKIN \\ Department of Architecture, Obafemi Awolowo University, Ile-Ife, Nigeria \\ E-mail: adconsul@yahoo.com, logunsha@oauife.edu.ng.com \\ Tel: 23-48-032-323-637, 23-48-037-116-387
}

\begin{abstract}
Every culture produces its own house-form, highly reflective of the history and lifestyle of its people. The family house is a symbol of social identity and family recognition; the need to preserve people's culture and history through their house is crucial to achieving sustainable housing and decent livelihood. One major concern of urban sociologists and anthropologists, and those in housing related disciplines, is how to provide adequate shelter for the wellbeing of the people. This study thus attempts to examine the place of the family house in Oyo town, Nigeria. A survey of existing family house structure was conducted on households and their housing peculiarities to determine residents' dwelling preferences. The study showed that despite noticeable inadequacies and deplorable conditions exhibited by most dwellings in Oyo town, the people had strong inclination towards their houses. The study concludes that traditional architecture is not opposed to modernity if both are mutually and rationally initiated. To achieve sustainability in housing, relevant aspects of people's culture and history, inherent in their dwellings should be incorporated into contemporary housing development.
\end{abstract}

Keywords: Place, Housing-preference, Family-house, Oyo town, Nigeria

\section{Introduction}

Adequate shelter has always been one of the very basic human needs. Overtime, its provision has been met in the form of dwellings which are temporary or permanent, natural or adapted (Ojo, 1998). However, housing is more than shelter (Wahab, 1983; Oladapo, 2006). It is a permanent structure for human habitation, and has become a critical component in the social, economic and health fabric of every nation. Its history is thus inseparable from the social, economic, cultural and political development of man (Listokin et al., 2007).

Studies have shown that the provision of appropriate housing, particularly for the urban poor constitutes a major challenge to development in most African countries and developing nations at large (Okoye, 1990; Lawanson, 2005). Studies have also shown that one of the major problems confronting housing development in the urban areas of most developing countries, is the neglect of people's values and cultures inherent in their traditional dwellings. In this case, attention is paid to the building's physical appearance rather than its functions and adaptability to the occupants (Gyuse, 1993; Adedokun, 1999; Jiboye, 2004). Since culture and tradition are not opposed to modernity if both are rationally and mutually initiated, housing design that contradicts user's preferences and lifestyles would invariably lack originality and relevance (Awotona et al., 1994).

It has however been established that housing has the potential to contribute towards all aspects of life and development in the individual, community and national context (Oladapo, 2006). Housing is thus viewed as a major barometer for measuring economic development by enhancing economic performance and place competitiveness. The role it plays in enabling both growth and regeneration will therefore need to be closely aligned, and the capacity to deliver housing of the right type, in the right place, and to an acceptable standard, is essential to the health and sustainability of cities and national economy (Ajanlekoko, 2001; Douglass, 2008; HC, 2008). There is no doubt however, that housing remains a basic human need. Its quality, cost, and availability are crucial to individual's quality of life. Also, the location, planning, layout and design make an important contribution to community spirit and identity, and are significant components of the social dimension of sustainable development (NAHA, 2006).

In many parts of the world, particularly in the western part of the sub-Sahara Africa where Nigeria lies, the indigenous housing patterns usually reflect the traditions of the various tribes, the family life and the significance of the natural environment of the people (Osasona et al., 2007). For instance, the courtyard compound house-types of the Yorubas, Ibos and Bamilekes in the forest region; the flat roof mud compound house of the Hausas, and the scattered huts of the Moufous and Sombas in the savanna region of west Africa are all typical examples of traditional architecture which reflect the lifestyles and adaptations of the people to their natural environment (Adedokun, 1999). In contemporary time, man builds more than basic shelter for housing; the dictates of present day urban life, influence of western culture and technological advancement have all affected house types in many developing nations (Mills-Tettey, 1989). Consequently, most of the houses emanating from this process lacked social and cultural relevance to the occupants (Muller, 1984). However, the house is a product and reflection of man's civilization and history, the need for its preservation in the face of evolving modernity and development is critical to the achievement of stable and sustainable human and national development. 
One of the primary objectives of the principle of sustainable development as contained in the Brundtland Report of 1987 relates to ways of ensuring a better quality life for everyone, now and for generations to come (HC, 2003; NAHA, 2006). This entails a process of building our communities so that we can live comfortably by providing lasting and secure livelihoods which minimize resource depletion, environmental degradation, cultural disruptions and social instability (Jiboye, 2009a; Akiyode, 2009). Since housing occupies a central position in the sustainable urbanization agenda in Nigeria and other developing nations; and also since African traditional family housing unit constitutes a significant component of the urban housing stock, there is the need to ensure its adequacy in other to facilitate a better quality life as well as maintain stable urban communities.

Considering the importance of the family house in the context of African traditional architecture, and the fact that relevant input and intervention from housing technocrats - including sociologists and anthropologists in urban housing development have not been accorded any significant consideration; not much has been done through research to examine the place of the family house. Whereas, the traditional family institution in Africa constitutes a major factor in enhancing both social and cultural integration in sustainable urbanization, the input of studies such as this is therefore required to justify the basis upon which relevant aspects of indigenous architecture are incorporated into contemporary and future housing design and development. Such input will also aid in enhancing the promotion of the family lifestyles within the fast growing urban setting like Oyo town in Southwestern part of Nigeria.

\subsection{The house in traditional African context}

The house, according to Williams (2007) is a dwelling place, constructed as a home for one or more persons, whether a crude hut or a mansion, and whatever its degree of intrinsic architectural interests, it provides protection from the weather and adversaries. Godwin (1998) has defined the house as "the space that we can call our own, that gives us privacy and shelters us from the weather and intrusions of unwanted people". The house is thus an important investment which has become a status symbol and a symbol of tradition. A man's position in the society, occupation and other resources tend to affect the house he builds for himself (Mills-Tettey, 1989; Olayiwola, et al., 2006).

The house or dwelling unit to the typical African, is not just providing protection from inclement weather and a social interaction forum, it is also a setting for pursuing a livelihood; a place for communicating with the ancestors and a nucleus for organic extension (Osasona et al., 2007). And because the essence of the house is not limited to shelter alone, it is a space where a generation of families expresses its existence and preserves the history and identities of lineage. The family house is thus a symbol of social identity and community recognition. A house without the members of the family lineage living in it loses respect in the community (Awotona et al., 1994).

It has however been observed that certain factors determine the pattern and development of house-forms within the traditional African context. Osasona (1998) observed that both socio-cultural and environmental factors constitute major determinants of house-form. Williams (2007) also observed that the physical characteristics of the house depend on the surrounding environment, available building materials, technological know-how, and some cultural determinants like the social and economic status of the owner. In addition, a typical dwelling is generally a product of physical constraints and social parameters. In African traditional built-form, symbolism was a dominant feature which is synonymous with function - the purpose to which both material and space could be put; and culturally-embedded interpretations of space-related phenomena - which relates to the determination of spatial pattern and organization, and the choice of construction materials (Osasona et al., 2007). The need for the preservation and promotion of cultural values through housing designs and development is therefore critical to the realities of achieving sustainable human settlements. Though an assessment of the social and cultural values in housing does not fall within the scope of this study, as such, the understanding of the place and relevance of the house requires an examination of the nature of the traditional Yoruba house in Nigeria.

\subsection{The Yoruba Family house in Nigeria}

In many regions of the sub-Saharan Africa, the natural environment is sometimes severe; consequently, the architecture in these areas has been adapted to suit the natural environment. Though, several fundamental differences exist between all the geographical environments of the regions in terms of the physical environment and cultural practices, all of these have significant influence on the traditional architecture of these areas. The housing patterns which exist as single, clustered and compound in nature are outcomes of the people's traditions and influence on the natural environment.

In Nigeria, as in other places, the characteristics of traditional architecture vary with materials, construction, shapes and styles from one area or community to another. However, given a definition of the family house in the context of the Yoruba traditional architecture, Adedokun (1999), describes it as "that occupied partly or solely by persons whose rights of residence derive directly from common ancestors". It is the house to which the family belongs, and this exists in four different categories. The first category is the oldest, and through time and prolonged association, became identified as the original family house where everybody belongs. Virtually in Yoruba land, everyone within the race belongs to one house typically referred to as "Orirun", meaning "origin or 
source of the ancestors", and sometimes also referred to as "Agbo ile", meaning "Flock of houses". The second category is that which is converted to family house upon the death of the original owner and head of a nuclear family. Upon the owner's death, the house then passes down to other members of the extended family as inheritance. The third category of the family house is the one built by a wealthy member of a particular extended family and subsequently decided to allocate certain parts of the house to his or her relations out of free-will. Whereas, the fourth category, is that built through communal inputs from every member of an extended or nuclear family. Typically, the Yoruba race is highly organized socially, culturally and politically. These attributes are reflected in their house-form. However, a cursory examination of the morphology of the traditional family house in Yoruba presents a unique and intriguing adherence to culture.

The "Yorubas", as generically referred to, build compound architecture, having a basic form that is cuboidal with a rectangular inpluvial court-yard located within the compound. As a typology, the Yoruba house is well-known for its arrangement of rectilinear spaces around a central courtyard which acts as the focal point and a place of interaction among family members. Aside from this function, the open courtyard also serves as a means of moderating the micro-climate. Preceding the major courtyard is the "akodi", which served as an entry porch. This is a reception area for receiving visitors and also serves as the rallying-point for the discussion of family matters and for major festivities (Osasona, 1998).

Some of the features of the compound grouping is worthy of note. (Figure 1 illustrates a typical Yoruba house). Around the courtyard is the gallery or verandah, referred to as "oode", which provides visual continuity and from which the rooms are accessed. In most cases, there are no windows for the rooms, but wherever there is any, it is usually very small in size. The front entrance to the house leads into a central courtyard. However, it is not unusual to have more than one courtyard in the Yoruba compound architecture and this depends on the social status of the household head. The saddle-shaped roof is typical of Yoruba traditional architecture and this provides very deep covering for the internal verandah. Apart from the rooms and other spaces created around the courtyard, there is an additional space in the ceiling for storage purposes (Amole, 1998).

Usually, the Yoruba house is built with earth material in layers to make walls which bear the timber trusses, thatched covered roof. However, the construction of the family house to the Yorubas requires little skill, and every man was a sufficient architect for the job, while the whole community lent a hand in the construction (Ojo, 1998). The basic geometry adopted in the Yoruba traditional architecture is a manifestation of the interplay between culture and architecture. The spatial arrangement of the rooms in hierarchical order reflects the level of family ties and social order, as the household head occupies the room near the entry gate to provide surveillance and security. (Adedokun, 1999).

\subsection{A brief background of Oyo town}

Oyo is one of the prominent Yoruba towns in southwestern part of Nigeria (Figure 2). It is located between latitude $7^{0} \quad 23^{\mathrm{I}} \quad$ north of the equator, and longitude $3^{0} \quad 27^{\mathrm{I}}$ east of the Greenwich Meridian. The land area is 784 feet above sea level and has a distance of about $50 \mathrm{~km}$ away from Ibadan - the most densely populated city in sub-Saharan Africa. The preset day Oyo town metamorphosed from the ancient Oyo Empire which was founded in the mid $17^{\text {th }}$ century. At that time, it served as the capital of the Oyo kingdom (Wikipedia, 2009).

The old Oyo Empire covered a wide area between the Volta and Niger rivers. Administratively, it was headed by the Alafin (King). According to history, the contemporary Oyo town originated from the Yoruba town of Ile-Ife - generically referred to as the origin of the Yoruba race. This claim is evident by the similarities of their culture, living and housing characteristics, language, family structures, traditional beliefs and lifestyles. However, the transitional nature of human society implies that specific cultural structures and lifestyles of a people are susceptible to changes and influences under the dynamics of social transformation (Awotona et al., 1994). Oyo town is a partially urbanized medium city, and the effects of urbanization on the city have not created much contradictions between the "old and the new". The old and new Oyo are two cultures which mutually coexist in the area of housing and socio-economic intercourses.

Oyo, like every other Yoruba towns exhibits three patterns of spatial morphology namely; the core area, intermediate area and the outer periphery (outskirt). The core area is an extensive central space dominated mainly by the king's palace and an open market - referred to as "oja oba", meaning, king's market. Administratively defined residential quarters and zones of agricultural production were deployed around the central space (Mabogunje, 1962). The core and parts of the intermediate area demonstrate features of the old, while the outskirts exhibit features of the new in the housing typology and availability of basic social infrastructure. However, the incursion of colonial administration and subsequent period of independence brought about the growth of contemporary Oyo town. Today, going by the 2006 census count, the latest population figure of the areas that make up the new Oyo town is about 368,194 (NPC, 2006).

\subsection{Aims and Objectives of the study.}

The study intends to examine the place of the family house in contemporary Oyo town, Nigeria. This is with a view to justify the relevance of indigenous dwellings and traditional architecture in promoting sustainable livelihood as well as in enhancing both social and cultural integration of the people towards sustainable 
urbanization. Consequently, the main objectives of this study are to examine households' characteristics and structure of the family house; assess physical characteristics and condition of the family housing unit in Oyo, and based on these evaluations; determine households' preferences for the dwellings. The outcome of this study will serve as useful feedback upon which relevant aspects of indigenous architecture could be incorporated into contemporary and future housing design and development in Nigeria.

\section{Methodology of study}

A survey of existing family house structure was carried out on selected households within the core area of Oyo town, Nigeria. However, studies indicate that housing evaluation could be done using variables such as households' characteristics, dwellings and neighborhood amenities, dwellings physical attributes, and users' preferences (Kearney, 2006; Hur and Morrow-Jones, 2008; Jiboye, 2009b). These variables will be employed to determine the peculiarities of the dwellings and residents' housing preferences for this study. Samples were collected using a questionnaire containing 27 items, classified under these variables to elicit relevant information for this study. Like any typical Yoruba town in southwest Nigeria, Oyo consists of three areas of residential development. These are; the inner traditional core area, the intermediate or transitional area, and the periphery, or area of newer residential districts (Onokerhoraye, 1977; Egunjobi, 1995; Jiboye, 2004). The survey focused on the core area of Oyo town where traces of existing family houses are found. Out of the 62 typical family houses identified and administered with questionnaires, only 40 questionnaires - representing 64.5\% response rate were actually retrieved from the households for analysis. This proportion is considered to be very adequate according to Idrus and Newman, cited in Oladapo (2006), who indicated that a response rate of $30 \%$ is adequate for evaluation purposes. In addition, the respondents' mean length of stay in their houses was 15 years, indicating that on the average, they had lived in their dwellings long enough to enable them provide relevant information about their house. The data were analyzed with the SPSS software, using frequency distribution and percentile methods of analyses. The formula for the percentile method as computed by SPSS is given as:

$$
\left(f_{i} \times 100\right) / n
$$

where: $f_{i}$ is the frequency of responses; and $n$ is the total number of respondents in the sample. Further analysis of the data obtained was carried out using the analysis of variance (ANOVA) test to explain the linear relationship and determine the level of significance between households' characteristics and residents' preference for the family house. The result is established at both 0.01 and 0.05 probability levels. Photographic illustration was employed to enhance the findings of this study, while the head of each household or his representative provided relevant information for the survey.

\section{Data analysis and results}

The analysis and discussion of result are based on the assessment of some households' characteristics which have been identified from relevant literature (Kearney, 2006; Hur and Morrow-Jones, 2008). These include; respondents' age, sex, and marital status, place of origin, occupation, income, household size, house ownership status and length of stay within the house. Other variables identified from literature (Jiboye, 2009b), and assessed for dwellings and neighborhoods attributes include; place for cooking and toilet facilities, water and electricity supply, drainage system and road network, dwellings' physical appearance, spatial pattern, walls and roofs' condition. Tenants' housing preference was assessed based on the ratings of these variables. The results are as presented below.

\subsection{Households' characteristics}

A brief analysis of households' characteristics presented in Table 1, shows that 85\% of the respondents (household-heads) living in the existing family houses in the study area were 60years old and above. From this proportion, $90 \%$ were males, of which $95 \%$ of them were married. Notably, all the respondents $(100 \%)$ were original indigenes of Oyo town, having about $97.5 \%$ of them who have been occupying their houses for over 30 years. With regards to the occupational status of respondents, $37.5 \%$ engaged in peasant farming, while $30 \%$ were engaged in petty trading activities. Unexpectedly, the majority $(72.5 \%)$ of those interviewed had no formal education, while only $17.5 \%$ had the benefit of secondary education. Others $(10 \%)$ did not proceed beyond primary school level. Considering the income level of respondents, 70\% of them earned less than N20, 000 - an equivalent of $\$ 120$ per month. Only 30\% earned more, between N30, 000 and N40, 000 (240 US Dollars), per month. Almost all the respondents interviewed (97.5\%) claimed ownership of their dwellings. $60 \%$ of those in this category inherited their houses through their great grand fathers, $25 \%$ of them had their houses built by their grand fathers, while $15 \%$ had theirs built and transferred to them by their fathers. In each of these cases, house ownership was by inheritance, and a significant proportion $(60 \%)$ of the house had been in use for over 40 years. This confirms the pattern of home ownership among the Yoruba people, where such is inherited through lineage (Adedokun, 1999). Through this process, a generation of families expresses its existence and preserves the history and identities of lineage (Awotona et al., 1994).

Considering the structure of households in the study area as typical of Yoruba traditional family setting, there was a predominance of the extended family structure - consisting of the father, wife, children and other relatives or descendants (Jiboye, 2004). As evident by the dominant size of households, 52.5\% had between 5 to 10 
persons per household, while others (47.5\%) had more, as high as more than 10 persons depending on the number of wives and children available to each family.

\subsection{Dwelling and Neighborhood amenities}

This section focuses on the assessment of the amenities available to households in the sampled family houses. From Table 2, there is an indication that all the households (100\%) sampled from the study area had their cooking activities done within open sheds located behind their houses. To most households (65\%), pit latrines served as toilet facilities, while others $(35 \%)$ made use of alternative means or nearby bushes outside their dwellings. Access to pipe-borne water was out of the reach of the households as all the households sampled $(100 \%)$, got water mainly through dug wells located either in front or behind their housing premises. However, $90 \%$ of the houses were connected to electricity. Though, it is not uncommon in most cases as it is typical within most urban areas in Nigeria that power supply is either erratic or not available at all. It is glaring from the visual evidence in Figure 3, that most of the roads in the study area were bad and untarred, while the drainages were in a deplorable condition. This is supported by the fact that $92.5 \%$ and $95 \%$ of the respondents claimed that these amenities were actually in a bad condition. In supporting earlier claim by Olayiwola et al (2006), this finding shows the level of government insensitivity to the provision of basic social infrastructures for the people.

\subsection{Dwellings' characteristics and Housing preferences}

As indicated in Table 3, the survey showed that $97.5 \%$ of the respondents rated the physical conditions of their dwelling as good, whereas, only $2.5 \%$ of them considered it as bad. Considering the level of spatial adequacy and functionality of the dwellings, $85 \%$ and $100 \%$ of the respondents rated their dwellings as adequate and functional. Only $15 \%$ of them rated the spaces as inadequate. A significant proportion of the respondents (85\%) considered the pattern of their houses as aesthetically pleasing. Although, existing realities through visual evidence indicate that the design of most family houses in the study area have been altered to reflect contemporary "rooming" housing styles and patterns (see, Figure 4). However, 95\% of the respondents rated their dwellings' walls condition as degrading and unacceptable compared to just $5 \%$ of them who considered the walls condition to be good. To justify this opinion, the majority $(65 \%)$ of houses sampled had the walls unplastered and poorly finished. Nevertheless, a significant proportion $(92.5 \%)$ of the respondents rated the roofs' condition of their dwellings as good.

With regards to housing preferences, despite the shortcomings noticeable in the physical conditions of the houses, a significant proportion of the respondents $(85 \%)$ compared to those who were unsure $(35 \%)$, showed higher preference to continue to live in their houses. To support this claim, $85 \%$ of them expressed absolute reluctance to either relocate or change their houses. Though, all those interviewed (100\%) agreed to the fact that their houses need one form of improvement or the other, as indicated by the generally poor and deplorable environment. (See, Table 4c, and Figure 5). Apart from the overall improvement required for the dwellings, there is a need for the creation of additional spaces for decent toilet and kitchen activities as well as the provision of portable water and steady electricity.

Further analysis of the results was carried out using the analysis of variance (ANOVA) test to explain the linear relationship and verify the level of significance between housing preferences (dependent variable) - indicated by; prefer to live in dwelling and desire to relocate [see, table 4(a and b)], and households and respondents' characteristics (independent variables). The results ( $\mathrm{F}$ - values) of the test presented in Table 5 show that significant and linear relationships exist between households' "choice to live in dwellings" and respondents' sex ( $\mathrm{F}=102.6 ; \mathrm{P}<0.01)$, occupation ( $\mathrm{F}=6.51 ; \mathrm{P}<0.05)$, income $(\mathrm{F}=8.87 ; \mathrm{P}<0.01)$, and ownership status of dwellings $(\mathrm{F}=17.58 ; \mathrm{P}<0.01)$. The results also show that significant and linear relationships exist between households' desire to relocate and respondents' age $(\mathrm{F}=36.14 ; \mathrm{P}<0.01)$, sex $(\mathrm{F}=16.88 ; \mathrm{P}<0.01)$, marital status $(\mathrm{F}=16.65 ; \mathrm{P}<$ $0.01)$, occupation $(\mathrm{F}=6.72 ; \mathrm{P}<0.05)$, educational status $(\mathrm{F}=20.69 ; \mathrm{P}<0.01)$, average income $(\mathrm{F}=3.52 ; \mathrm{P}<0.05)$, duration of Occupancy $(\mathrm{F}=5,55 ; \mathrm{P}<0.01)$, ownership status $(\mathrm{F}=17.58 ; \mathrm{P}<0.01)$, and age of buildings $(\mathrm{F}=4.37$; $\mathrm{P}<0.05$ ). Other variables like residents' town of origin and household size are not statistically significant, and as such not determinants of housing preferences in the study area. These results indicate that residents' preference for the family house in Oyo is to large extent influenced and determined by both households and respondents characteristics. The finding of this study justifies the need to consider the nature and values of households in the provision of appropriate dwellings for the people.

\subsection{Discussion of findings}

From the foregoing analysis, the households' characteristics, conditions of family dwellings and neighborhood amenities have been examined. Also examined are the housing characteristics as well as respondents' preferences for their dwellings in the study area. The study has demonstrated the uniqueness of the family house to its occupants in Oyo township. The finding has shown that more of the older people than the younger ones constitute households heads in the study area, and that a significant proportion of those in this category were married males. By supporting Olayiwola et al (2006), the finding explains the extent to which men traditionally dominate household heads in most cultures in Nigeria. It also explains the level of family integration among most Yoruba households in Nigeria, as the incidence of divorced or separated households is minimal among the 
respondents in the study area. The finding further showed that a significant proportion of households had been living in their domain for quite over thirty years. However, there are indications that most of them were peasant farmers and petty traders who had little or no formal education but lived on a meager income at an average of about \#20,000 (\$120) a month. Significantly, house ownership is by inheritance, and this to some degree, helps promote extended family structure which is typical of the Yoruba culture in Oyo town, Nigeria.

Considering the level of adequacy of housing amenities available to households within the family house, it was found that most of these amenities were inadequate and sub-standard. Going by the results, cooking activity was done mainly in open sheds, while most of the residents used pit latrines. Also, facilities such as portable drinking water, steady electricity supply, good roads and drainages were not within the reach of most households. This finding supports those by Jiboye (2008: unpublished) and others, indicating the low level of government's commitment towards the provision of adequate social infrastructures to the people. It also supports Oladapo (2006) indicating the need for government intervention in the maintenance and improvement of both housing and urban infrastructure. The fact that most households in the study area lived on meager income thus suggests that they lacked adequate financial resource to either provide themselves with necessary amenities or improve the conditions of existing ones.

By assessing dwelling characteristics, it is however interesting to note that despite the poor physical conditions of most family dwellings in the study area - as indicated by the households' quest for housing improvement and supported by visual evidence, quite a significant proportion of the residents had a very strong preference for their houses. This opinion is also explained by the result of analysis of variance (ANOVA), revealing that residents' housing preferences (indicated by; prefer to live in dwelling and desire to relocate) were influenced and determined by their personal and households' characteristics. To them, the family house meant more than mere shelter. This goes further to explain Godwin (1998), Osasona et al (2007) and others, that the house is a symbol of social identity and community recognition, a setting for pursuing a livelihood and the nucleus for physical, organic extension. Likewise, it is a space within which a generation of families expresses its existence and preserves its history and identities. Perhaps, one of the significant implications of the study findings to housing development is in showcasing the family house as an important component of the housing stock in any given society, as such; its existence and values need to be preserved and integrated into the overall urban housing structure.

\section{Conclusion and Implication of study}

This study has examined the place of the family house in Oyo, Nigeria. Among the variables assessed for the study are households' characteristics, conditions of dwellings and neighborhood amenities. Also assessed are the housing characteristics as well as respondents' preferences for their dwellings in the study area. One of the major findings of this study is that ownership of the family house in Oyo town is through inheritance from households' progenitors. This is the means by which each family lineage; history and existence are preserved, and this is particularly the case in most traditional communities in Nigeria and other parts of sub-Saharan Africa. The study showed that despite lack of, or inadequacy of basic housing and social amenities like water, electricity, roads, drainages, toilet and kitchen spaces in the dwellings, most households have demonstrated through their ratings that the family house to them represents a symbol of social identity and community recognition, and regardless of the existing deplorable condition of their dwellings, would prefer to live there. In validating the result of this study, the analysis of variance (ANOVA) test further confirms that households' and respondents' characteristics have significant relationship with housing preferences in Oyo town. While substantiating Awotona et al., (1994) and Osasona et al., (2007), these findings thus suggest that people's culture and history are very relevant in the determination of appropriate dwellings, and as such, needs preservation through the family house - since it has been admitted that traditional principles and ideals are not antagonistic to modernity if both are mutually and rationally initiated.

In contemporary time, a major parameter for defining house-form in most African communities is the adoption of western technology and style which sometimes does not aid sustainable housing development in the traditional African context, since traditionally, the technology that produces a building also maintains it (Osasona, 1998). It is noteworthy that despite the acceptance and integration of modern culture, the "Yorubas" still maintain their string ties with tradition through their traditional architecture. Therefore, in defense of the principle of sustainable development, housing sustainability involves a process of building communities in order to live comfortably by providing lasting and secure livelihoods which minimize resource depletion, environmental degradation, cultural disruptions and social instability (HC, 2003; Jiboye, 2009a; Akiyode, 2009). Rather than providing housing which lacks spatial relevance to its occupants, new housing development must consider relevant aspects of traditional architecture that could enhance qualitative and sustainable livelihood particularly for the urban poor. To achieve this requires collaborative efforts by both policy makers and planners alike, in formulating a responsive housing policy which will integrate housing designs with the physical, socio-economic and cultural peculiarities of the people. Since African traditional family housing unit constitutes a significant component of the urban housing stock, there is the need to ensure its adequacy in other to facilitate qualitative and stable urban communities. There is no doubt that households are major stakeholders in housing 
improvement and maintenance (Oladapo, 2006). While efforts are needed in mobilizing people for this purpose, government's involvement is also required in housing improvement - particularly as regards provision of basic amenities in cities where traditional dwellings exist.

Although the transitional nature of human society implies that specific cultural structures and lifestyles of a people are susceptible to changes and influences under the dynamics of social transformation (Awotona et al., 1994). In the case of Oyo town, the effects of urbanization on the city have not created much contradictions between the "old and the new" cultures which mutually coexist in the area of housing and socio-economic intercourses. This has significant implication for residential development in Nigeria. Rather than abandoning indigenous house-types and providing new dwellings which are unfit and inadequate for the people, the Oyo experience justifies the need to integrate existing indigenous house-types into contemporary ones as well as consider relevant aspects of traditional architecture in contemporary and future house designs. Any effort along this direction is deemed necessary towards ensuring that traditional dwellings are not completely abandoned as mere "refuse dumps".

\section{References}

Adedokun, A. (1999). Perspectives on African Traditional Architecture and Planning. SEDEC Publishers Lagos, Nigeria.

Ajanlekoko, J.S. (2001). Sustainable housing development in Nigeria - The financial and infrastructural implication. International Conference on Spatial Information for Sustainable Development. Nairobi, Kenya. 2-5, October. [Online] Available: www.fig.net/pub/proceedings/nairobi/ajanlekoko - CMWS1-1.pdf. (March, 27, 2009).

Akiyode, O. O. (2009). Gender, sustainable peace, and development in the Niger Delta region of Nigeria Journal of Sustainable Development in Africa. Pennsylvania. 11, (2), 224-236.

Amole, B. (1998). Social classification of domestic space. A comparative analysis of Hausa and Yoruba urban dwellings. In, B. Amole (Ed.), Habitat Studies in Nigeria. Some qualitative dimensions. (pp. 142-151). Shaneson Publishers. Ltd. Ibadan, Nigeria.

Awotona A., Ogunshakin L. and Mills-Tettey, R. (1994). Multi-Habitation and Cultural Structures. Experiences from Nigeria. Book of Readings. Dept of Architecture Obafemi Awolowo University, Ile-Ife, Nigeria and CARDO. Newcastle, U.K.

Douglass, S. (2008). Forward on Housing and economic development. Housing Corporation. UK. [Online] Available: http://www.housingcorp.gov.uk/htm (March, 15, 2009).

Egunjobi, L.(1995). "Osogbo: Aspects of Urbanization, Physical Planning and Development. In, C. O Adepegba (Ed.), Osogbo: Model of growing African Town. (pp. 14-19). Institute of African Studies, University of Ibadan, Nigeria.

Godwin J. (1998). The House in Nigeria. An Exploration. In, B. Amole (Ed.), Habitat Studies in Nigeria. Some qualitative dimensions. (pp. 1-10). Shaneson Publishers Ltd. Ibadan, Nigeria.

Gyuse T.T. (1993). Socio-Cultural Dimension of Public Housing. In, R. W. Taylor (Ed.), Urban Development in Nigeria Planning, Housing and Land Policy. (pp. 154-161). Ave Burry Publishers. Montclair State, New Jersey U.S.A.

Housing Corporation of Britain (HC), (2003). Sustainable development strategy [Online]. Available: http://www.housingcorp.gov.uk/htm (March, 15, 2009).

Housing Corporation of Britain (HC), (2008). The role of housing in shaping the economic performance: Housing and economic development. Survey Report. Available: http://www.housingcorp.gov.uk/htm (March, 15, 2009).

Hur, M. and Morrow-Jones, H. (2008). Factors that influence residents' satisfaction with neighborhoods. Environment and Behavior. 40 (5), 619-635.

Jiboye, A. (2004). The Socio-cultural responsiveness of household-size on Housing quality in Osogbo, Nigeria. The Anthropologist. 6 (3), 169-174.

Jiboye, A. D. (2009a). The Challenges of Sustainable Housing and Urban Development in Nigeria. In, P. A. Ilenikhena et al. (Eds), Contemporary challenges in research and sustainable development of the Third World. 5 (7). (pp. 3-8). IRDI and Kan Publishers, Uyo, Nigeria.

Jiboye, A. D. (2009b). Evaluating tenants' satisfaction with public housing in Lagos, Nigeria. Town Planning and Architecture. 33. (4), 239-247. [Online]. Available: http://www.tpa.vgtu.lt/ pdf. Adobe Reader. (February, 10, 2010).

Kearney, A. R. (2006). Residential development patterns and Neighborhood satisfaction: Impacts and density and nearby nature. Environment and Behavior. 38 (1), 112-139. 
Lawanson, T. O. (2005). Challenges of Sustainability and Urban Development in Nigeria: Reviewing the Millennium Development Goals. In, W. Fadare et al. (Eds), Globalization, Culture and the Nigerian Built Environment. Vol. II. (pp. 366-372). Obafemi Awolowo University, Ile-Ife, Nigeria.

Listokin, D and Burchill, R. (2007). Housing (Shelter). Microsoft student (DVD) Redmond. W. A. Microsoft Corporation. [April, 5, 2009].

Mabogunje, A. (1962). The Yoruba Towns. University of Ibadan Press. Ibadan, Nigeria.

Mills-Tettey, R. (1989). Climate, Environment and Indigenous Construction in Nigeria. A survey of some house forms. Housing Science. 13, 31.

Muller, M. S. (1984). Traditional Cultural Identity in new dwellings of urban Africa. Ekistics, 307, 355 - 360.

National Affordable Housing Association (NAHA) (2006). Sustainability; Policy Areas. [Online]. Available: http://www.housingcorp. gov. uk. (March, 5, 2009).

NPC. (2006). Official Census Figures. National Population Census. Federal Republic of Nigeria.

Ojo, J. R. O. (1998). Description of houses in Nigeria by travelers and explorers - 1823 -1892. In, B. Amole (Ed.), Habitat Studies in Nigeria. Some qualitative dimensions. (pp.48-63). Shaneson Publishers Ltd. Ibadan, Nigeria.

Okoye, T.O. (1990). Historical development of Nigerian housing policies with special reference to housing the urban poor. In, P. Amis and P. C. Lloyd (Eds), .Housing Africa's Urban Poor. (PP. 73-86). International African Publisher Institute. New York. Internet Google search. [Online]. (Previewed version accessed, March, 23, 2009).

Oladapo A. A. (2006). A Study of Tenant Maintenance Awareness, Responsibility and Satisfaction in Institutional Housing in Nigeria. International Journal of Strategic Property Management. Vilnius Gediminas Technical University. 10, 217-231.

Olayiwola L. Adeleye A. and Jiboye A.D. (2006). Effect of Socio-cultural factors on Housing Quality in Osogbo, Nigeria. International Symposium on Construction in Developing Economies: New Issues and Challenges. Santiago, Chile. January 18-29.

Onokerhoraye,A.G. (1977). The Spatial Pattern of Residential Districts in Benin Nigeria. Urban Studies. 44, 291-302.

Osasona C. O. (1998). Traditional house-form and the symbol of value of space and material. In, B. Amole (Ed.), Habitat Studies in Nigeria. Some qualitative dimensions. (pp.66-77). Shaneson Publishers Ltd. Ibadan, Nigeria.

Osasona C. Ogunshakin L. and Jiboye A. (2007). The African Woman's right to security through sanitation. From the dwelling unit to the neighbourhood. International Forum on Right to Live in Africa. Trieste, 9 - 10 November. Wahab, K. A. (1983). More than shelter. Inaugural Lecture Series No. 59. University Press. University of Ife. Ile -Ife, Nigeria.

Wikipedia, (2009). Oyo. Wikipedia, the free Encyclopedia. Microsoft Google search (April, 20, 2009).

Williams, P. (2007). House (Architecture). Microsoft Encarta Corporation. (April, 15, 2009).

Table 1. Households' and Respondents' Characteristics

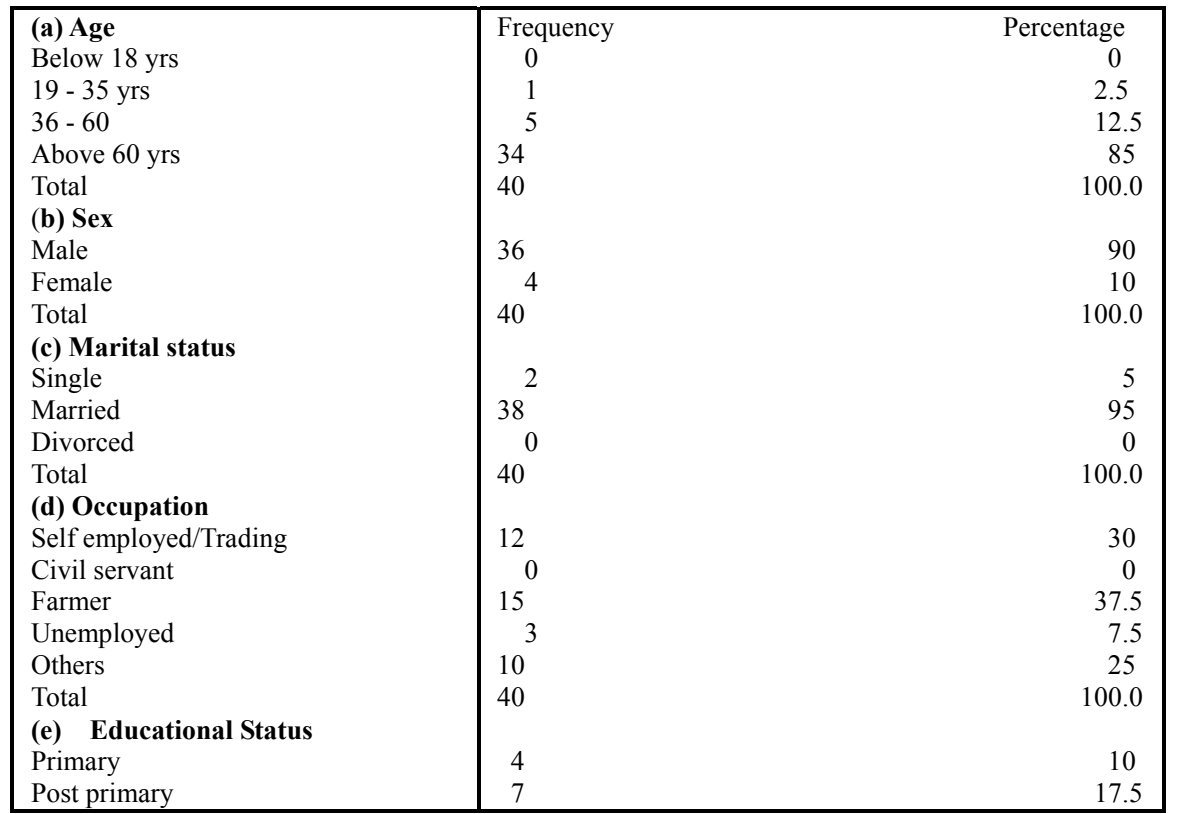




\begin{tabular}{|c|c|c|}
\hline Tertiary & 0 & 0 \\
\hline No formal & 29 & 72.5 \\
\hline Total & 40 & 100.0 \\
\hline (f) Average Income & & \\
\hline Below N10,000 $(<\$ 100)$ & 0 & 0 \\
\hline N11,000 - N29,000(@\$120) & 28 & 70 \\
\hline N30,000 - N40,000 (@\$240) & 12 & 30 \\
\hline Above N40,000 $\quad(>\$ 240)$ & 0 & 0 \\
\hline Total & 40 & 100.0 \\
\hline (g) Town of Origin & & \\
\hline Indigene of Oyo & 40 & 100 \\
\hline Non indigene & 0 & 0 \\
\hline Others & 0 & 0 \\
\hline Total & 40 & 100.0 \\
\hline (h) Duration of Occupancy & & \\
\hline $1-10$ years & 0 & 0 \\
\hline $11-20$ & 0 & 0 \\
\hline $21-30$ & 1 & 2.5 \\
\hline Above 30 & 39 & 97 \\
\hline Total & 40 & 100.0 \\
\hline (i) Ownership Status & & \\
\hline Owner & 39 & 97.5 \\
\hline Tenant & 0 & 0 \\
\hline Free occupant & 1 & 2.5 \\
\hline Total & 40 & 100.0 \\
\hline (j) Household size & & \\
\hline Below 5 persons & 0 & 0 \\
\hline 5-10 people & 21 & 52.5 \\
\hline Above 10 people & 19 & 47.5 \\
\hline Total & 40 & 100.0 \\
\hline (k) Age of Building & & \\
\hline $1-10$ years & 0 & 0 \\
\hline $11-20$ & 0 & 0 \\
\hline $21-30$ & 0 & 0 \\
\hline $31-40$ & 16 & 40 \\
\hline Above 40 & 24 & 60 \\
\hline Total & 40 & 100.0 \\
\hline
\end{tabular}

Authors, Field Survey, 2009.

Table 2. Dwelling and Neighborhood Amenities

\begin{tabular}{|c|c|c|}
\hline (a) Cooking Spaces & Frequency & Percentage \\
\hline Open shed behind house & 40 & 100 \\
\hline Within the building & 0 & 0 \\
\hline $\begin{array}{l}\text { Total } \\
\text { (b) Toilet Facility }\end{array}$ & 40 & 100 \\
\hline Water Closet & 0 & 0 \\
\hline Pit Latrine & 26 & 65 \\
\hline Outside the house & 14 & 35 \\
\hline $\begin{array}{l}\text { Total } \\
\text { (c) Water Sources }\end{array}$ & 40 & 100.0 \\
\hline Borehole & 0 & 0 \\
\hline Well & 40 & 100 \\
\hline Pipe-borne & 0 & 0 \\
\hline $\begin{array}{l}\text { Total } \\
\text { (d)Electricity supply }\end{array}$ & 40 & 100.0 \\
\hline Connected & 36 & 90 \\
\hline Not connected at all & 4 & 10 \\
\hline Total & 40 & 100.0 \\
\hline (e) Road network & & \\
\hline Tarred & 3 & 7.5 \\
\hline Untarred & 37 & 92.5 \\
\hline Total & 40 & 100.0 \\
\hline (f) Drainage system & & \\
\hline Good & 2 & 5 \\
\hline Deplorable & 38 & 95 \\
\hline Total & 40 & 100.0 \\
\hline
\end{tabular}

Authors' Field Survey, 2009. 
Table 3. Dwelling Characteristics

\begin{tabular}{|c|c|c|}
\hline (a)Physical condition of dwelling & Frequency & Percentage \\
\hline Good & 39 & 97.5 \\
\hline $\mathrm{Bad}$ & 1 & 2.5 \\
\hline Total & 40 & 100.0 \\
\hline (b)Spatial adequacy & & \\
\hline Adequate & 36 & 90 \\
\hline Not adequate & 4 & 10 \\
\hline Total & 40 & 100.0 \\
\hline (c)Functionality of dwelling & & \\
\hline Functional & 40 & 100 \\
\hline Not functional & 0 & 0 \\
\hline Total & 40 & 100.0 \\
\hline $\begin{array}{l}\text { (d)Visual appeal of dwelling } \\
\text { Pleasing }\end{array}$ & & \\
\hline Not pleasing & 34 & 85 \\
\hline Total & 6 & 15 \\
\hline $\begin{array}{l}\text { (e) Wall physical condition } \\
\text { Good }\end{array}$ & 40 & 100.0 \\
\hline $\mathrm{Bad}$ & 2 & 5 \\
\hline Total & 38 & 95 \\
\hline $\begin{array}{l}\text { (f) Wall plastering } \\
\text { Plastered }\end{array}$ & 40 & 100.0 \\
\hline Not plastered & 14 & 35 \\
\hline Total & 26 & 65 \\
\hline $\begin{array}{l}\text { (g) Roofs' condition } \\
\text { Good } \\
\text { Bad }\end{array}$ & 40 & 100.0 \\
\hline Total & $\begin{array}{l}37 \\
3 \\
40\end{array}$ & $\begin{array}{r}92.5 \\
7.5 \\
100.0\end{array}$ \\
\hline
\end{tabular}

Authors' Field Survey, 2009.

Table 4. Housing Preferences

\begin{tabular}{|c|cr|}
\hline (a)Prefer to live in dwellings & Frequency & Percentage \\
Yes & 34 & 85 \\
No & 0 & 0 \\
Unsure & 6 & 15 \\
Total & 40 & 100.0 \\
(b)Desire to relocate & & \\
Yes & 4 & 10 \\
No & 34 & 85 \\
Unsure & 2 & 5 \\
Total & 40 & 100.0 \\
(c)Need for housing & & \\
improvement & 40 & 100 \\
Yes & 0 & 0 \\
No & 40 & 100.0 \\
Total & & \\
\hline
\end{tabular}

Author's Field Survey, 2009.

Table 5. ANOVA test values showing linear relationship among variables of housing preferences in Oyo.

\begin{tabular}{lllll}
\hline Household's Characteristics & \multicolumn{2}{l}{ Prefer to live in dwellings } & \multicolumn{2}{c}{ Desire to relocate } \\
\hline & $\mathrm{F}$ & $\mathrm{P}$ value & $\mathrm{F}$ & $\mathrm{P}$ value \\
Age & 0.492 & 0.48 & 36.142 & $0.01^{* *}$ \\
Sex & 102.6 & $0.01^{* *}$ & 16.881 & $0.01^{* *}$ \\
Marital status & 0.163 & 0.69 & 16.65 & $0.01^{* *}$ \\
Occupation & 6.506 & $0.02^{*}$ & 6.72 & $0.03^{*}$ \\
Educational status & 1.139 & 0.29 & 20.688 & $0.01^{* *}$ \\
Average income & 8.867 & $0.01^{* *}$ & 3.515 & $0.04^{*}$ \\
Duration of Occupancy & 0.079 & 0.78 & 5.55 & $0.01^{* *}$ \\
Ownership status & 17.575 & $0.01^{* *}$ & 17.575 & $0.01^{* *}$ \\
Age of building & 2.171 & 0.15 & 4.373 & $0.028^{*}$ \\
\hline
\end{tabular}

Authors' Data Computation **Significant at 0.01

*Significant at 0.05 


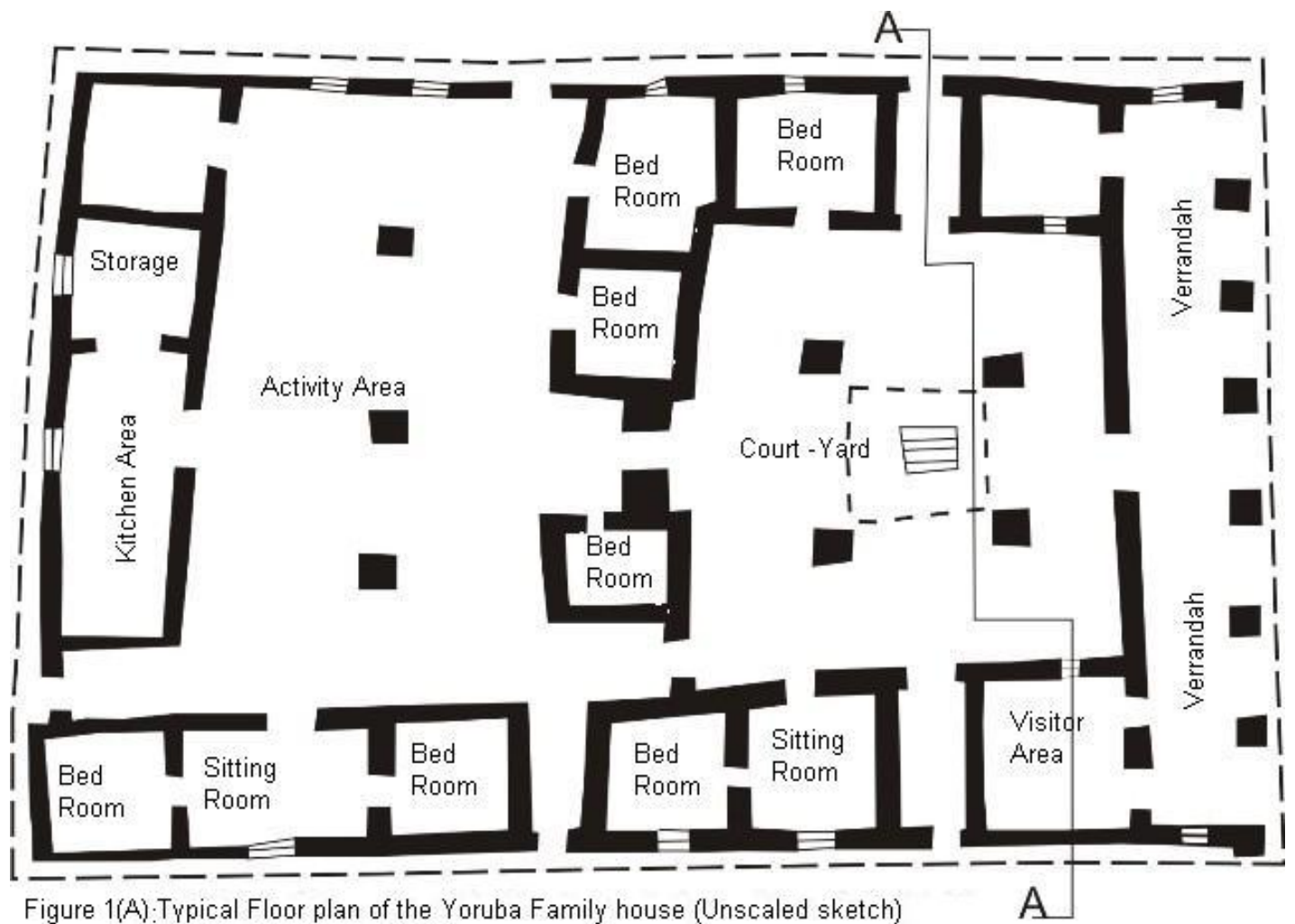
Source: Adedokun (1999).

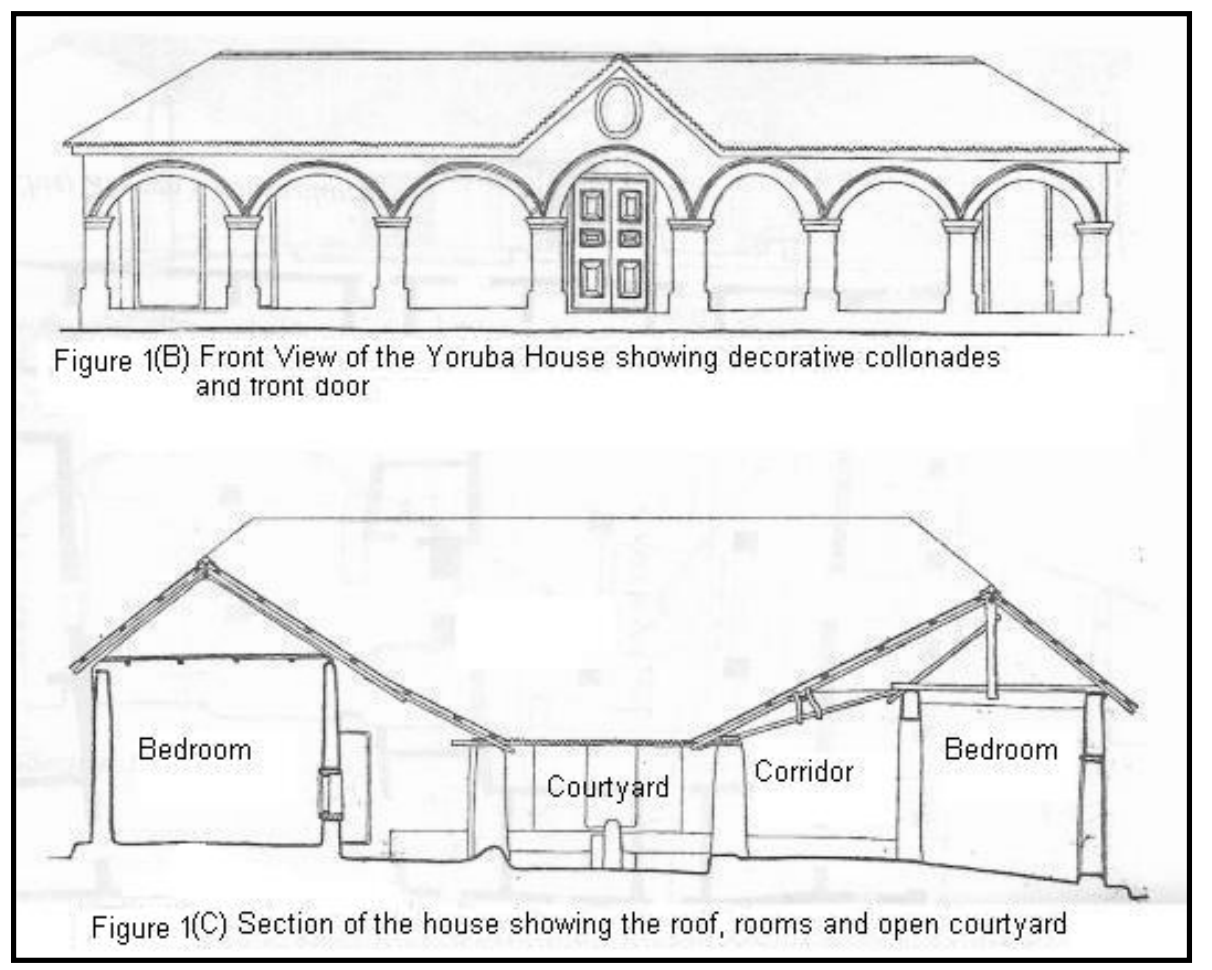



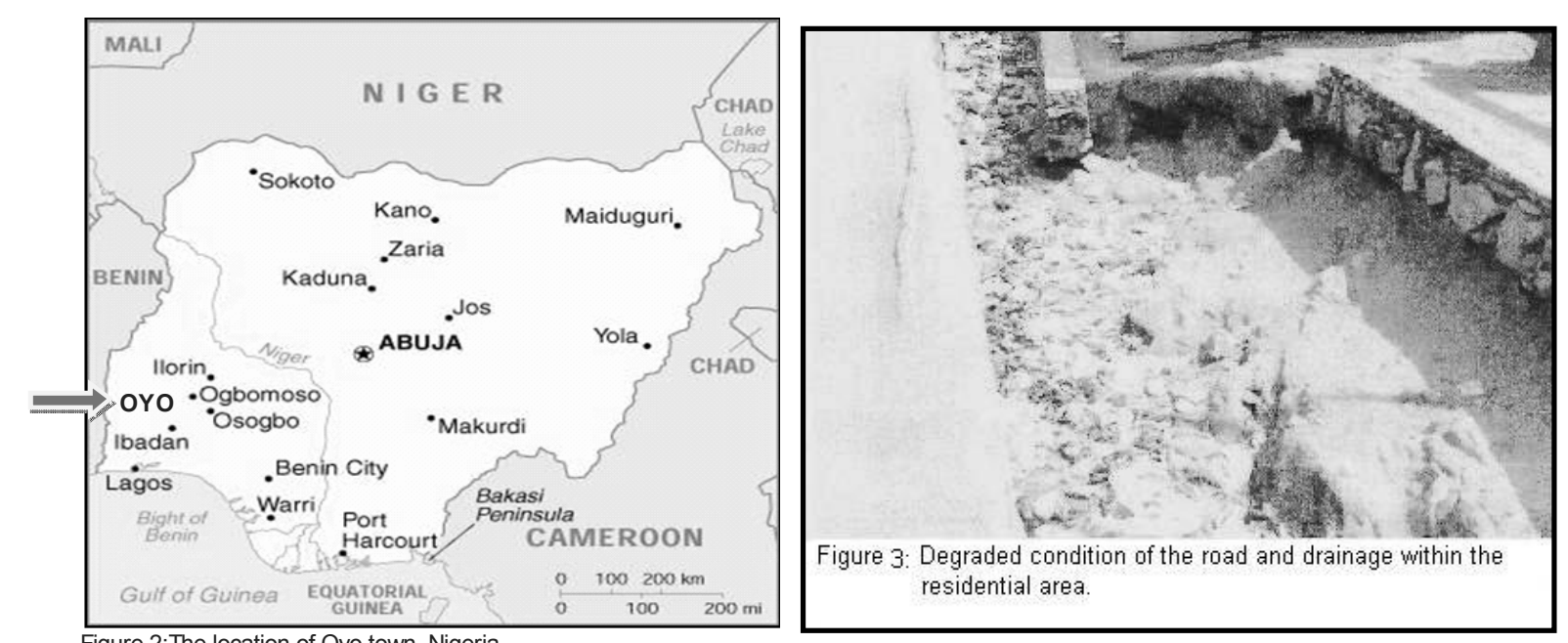

Source:Microsoft Encarta, 2007
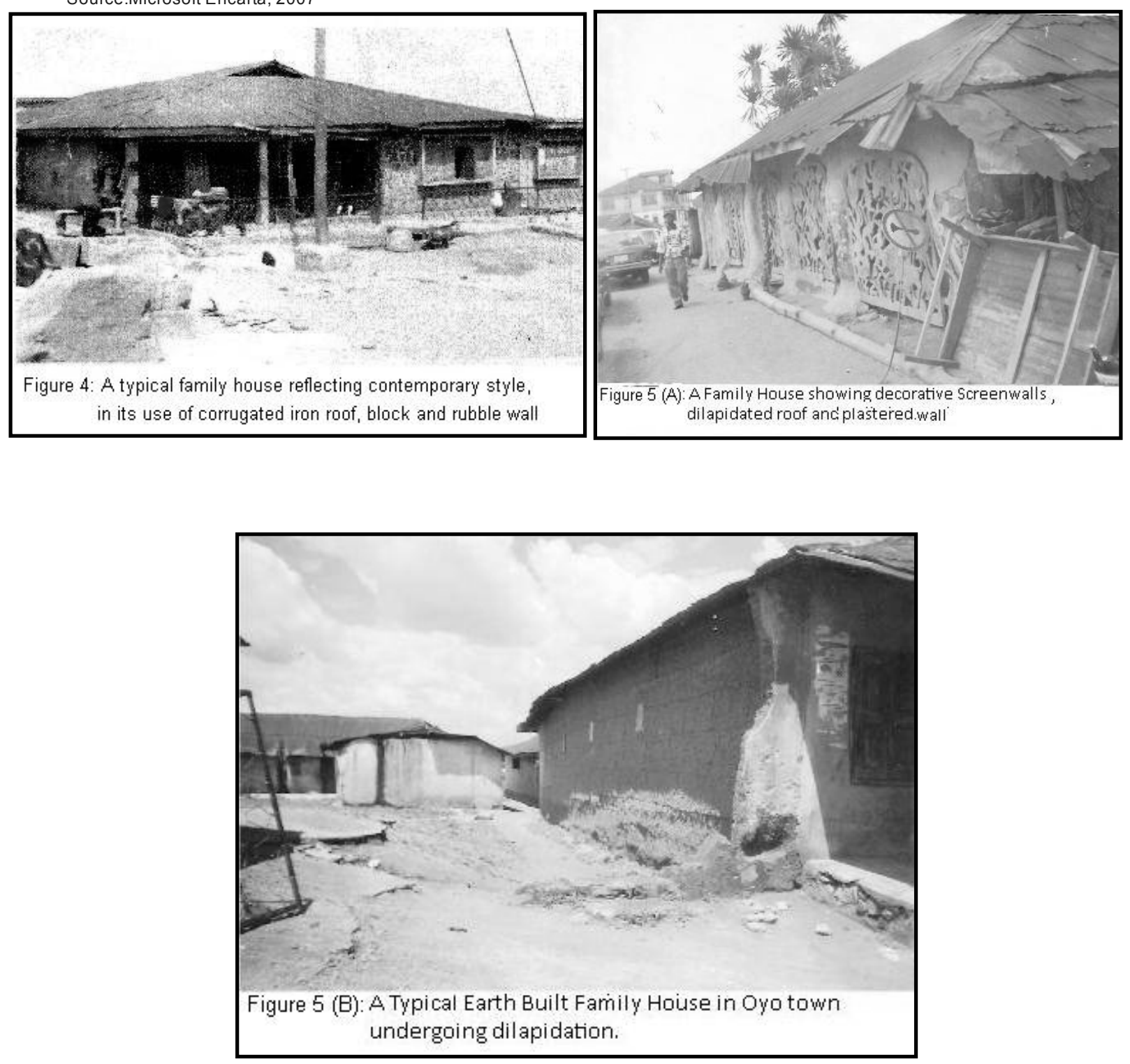